\title{
Presencia del canto gregoriano en la obra musical del compositor chileno Alfonso Letelier Llona ${ }^{1}$
}

\section{The Presence of Gregorian Chant in the Works of the Chilean Composer Alfonso Letelier Llona}

Este trabajo busca mostrar las distintas maneras en que el canto gregoriano es citado, elaborado o transformado en cuatro obras del compositor chileno Alfonso Letelier Llona (1912-1994) y los campos de significación que esto suscita en cada caso. Para ello, se toma en consideración a diversos referentes teóricos, como Hatten (1994), Nommick (2005) y López Cano (2018), y se aplica un marco analítico que abarca la poiesis y circulación de la obra, el discurso de recepción y el uso intertextual del canto gregoriano en ella.

Palabras clave: Alfonso Letelier Llona, música e intertextualidad, música académica chilena del siglo 20, canto gregoriano.

This article seeks to demonstrate the various ways in which Gregorian chant is quoted, developed or transformed in four works by the Chilean composer Alfonso Letelier Llona (1912-1994) and the areas of meaning generated in each case. To this effect, various theoretical references have been considered, such as Hatten (1994), Nommick (2005) and López Cano (2018), and an analytical framework applied comprising the poiesis and circulation of each work, the discourse of reception and intertextual use of Gregorian chant.

Keywords: Alfonso Letelier Llona, music and intertextuality, 20th-century Chilean art music, Gregorian chant.

\section{Introducción: música e intertextualidad}

Tal como afirma Robert Hatten², el estudio de la intertextualidad en música enriquece la comprensión tanto del proceso de poiesis de las obras o textos

\footnotetext{
${ }^{1}$ Este trabajo se enmarca dentro del Proyecto "La institucionalización de la modernidad de la música clásica como práctica social entre 1928 y 1973 en el marco de la Universidad de Chile", Fondo de Ciencia y Tecnología (Fondecyt), n. ${ }^{\circ}$ 1.160.102, cuyo investigador responsable es Luis Merino Montero. Por ello, dentro del marco teórico y metodológico, en este trabajo se toman en cuenta tanto estudios publicados acerca de la obra de Letelier como textos y documentos que se han generado a partir del mencionado proyecto.

${ }^{2}$ Robert Hatten: "El puesto de la intertextualidad en los estudios musicales", Desiderio Navarro (trad.), Criterios, 32, 1994, p. 212.
} 
musicales como el proceso infinito de sus interpretaciones. En el caso de la música del siglo XX, abordar este enfoque constituye casi un imperativo si se toma en cuenta, por ejemplo, la postura de Yvan Nommick ${ }^{3}$ :

El hecho de escribir música sobre música - popular o culta- o de reutilizar formas, técnicas o materiales temáticos pertenecientes al pasado es una "actividad citatoria asumida por los compositores desde hace siglos, porque para ellos está ligada al HACER musical y/o a los mecanismos de la reminiscencia". A lo largo del siglo XX, esta "actividad citatoria" se ha desarrollado considerablemente, ha tomado formas cada vez más variadas y sutiles, y se ha extendido en el tiempo y el espacio, tomando sus materiales tanto en la tradición europea -remontándose hasta la Antigüedad griega- como en las músicas extraoccidentales e incluso en la naturaleza [...].Además, este estudio intertextual es fundamental en el análisis de la música del siglo XX, y del naciente XXI, para comprender las relaciones entre el presente y el pasado, así como las interacciones entre la tradición y la modernidad que en ella se manifiestan.

Como expone Nommick, la "actividad citatoria" se remonta muy atrás en el tiempo, y es aquí donde tradiciones, géneros y repertorios como el canto gregoriano cobran importancia al intentar comprender esas "relaciones entre el presente y el pasado" o "entre la tradición y la modernidad”. Así lo plantea Rubén López-Cano"

La tradición de la música de arte occidental hunde sus raíces más importantes en la música religiosa [...]. En Europa, uno de los elementos seminales de la música clásica es el repertorio, prácticas y materiales del canto litúrgico regulado y gestionado por la doxa eclesiástica y que llamamos genéricamente como canto gregoriano y que servirá de base para la mayor parte de composiciones vinculadas a la práctica religiosa. La Iglesia no solo quería homogenizar sus prácticas litúrgicas en todos sus dominios, sino que aspiraba a construir toda una civilización coherente, integrada a ciertos valores y cosmovisiones autorizadas por ella. En esta empresa la música jugaría un papel determinante. Componer sobre el repertorio del canto gregoriano, emplear sus melodías como cantus firmus en la elaboración de complejas polifonías, no era una opción para el compositor: era una obligación. El compromiso sigue vigente en nuestros días en la órbita de la música religiosa. Por esta razón, la historia de la música medieval no es otra cosa que la historia de diferentes prácticas de apropiación, préstamos, reciclajes y reutilización de materiales obligatorios.

A partir de las palabras de Nommick y de López Cano, se infiere que el canto gregoriano mismo es una convergencia de "repertorio, prácticas y materiales" fundados en procesos intertextuales, y que las redes intertextuales

${ }^{3}$ Yvan Nommick: "La intertextualidad: un recurso fundamental en la creación musical del siglo XX", Revista de Musicología, 28, 1, 2005, pp. 799-800; 806.

${ }^{4}$ Rubén López Cano: Música dispersa. Apropiación, influencias, robos y remix en la era de la escucha digital, Barcelona, Musikeon, 2018, pp. 83-84. 
generadas en la música occidental a partir del mismo se extienden hasta los siglos XX y XXI. De aquí la pertinencia de considerar el caso de compositores del siglo XX y la relación que se establece en su música con el canto gregoriano.

En este marco cabrían ejemplos como el de Ottorino Respighi que en el segundo movimiento ("L'Adorazione dei Magi") de su Trittico botticelliano (1927) incorpora la melodía del himno Veni, veni Emmanuel5. O el caso de Benjamin Britten que abre ("Procession") y cierra ("Recession") su obra A Ceremony of Carols (1942) con la antífona Hodie Christus natus est, cuya melodía vuelve a citarse en el "Inteludio" para arpa sola en la misma composición ${ }^{6}$.Y por supuesto, el caso de Manuel de Falla que en el segundo movimiento ("Lento [giubiloso ed energico]") de su Concerto per clavicémbalo (ou pianoforte), flauto, oboe, clarinetto, violino e violoncello (1923-1926) aborda un material temático que remite tanto al Pange lingua more hispano, como a una entonación salmódica usada también por Haydn, Fux, Mozart y Mendelssohn?

En las obras de Respighi y Britten las piezas de canto gregoriano son incorporadas en la estructura musical como citas parentéticas, según la definición de López Cano : "La cita musical parentética nos remite a una pieza específica, singular y reconocible aunque se desconozca su nombre o autor. Se dice que son referencias parentéticas pues suelen ser puntuales, como un paréntesis, y ocupan un sitio breve y localizado dentro de la pieza de acogida”.

\footnotetext{
${ }^{5}$ Otras obras de Respighi que incorporan material de canto gregoriano son Tres preludios sobre melodías gregorianas (1921) para piano, Concerto gregoriano (1921) para violín y orquesta, y Quartetto dorico (1924) para cuarteto de cuerdas. Nathan Andrew Hess: Eclecticism in the Piano Works of Ottorino Respighi, tesis doctoral, Universidad de Cincinnati, 2005, p. 10.

${ }^{6}$ Kristin Ann Pfeifer: A Historical Analysis of Three Works for Trebles by Benjamin Britten, tesis de máster, Universidad Estatal de San José, 2002, pp. 23, 28 y 29

${ }^{7}$ Yvan Nommick: "Un ejemplo de ambigüedad formal: El 'Allegro' del 'Concerto' de Manuel de Falla", Revista de Musicología, 21, 1, 1998, p. 18; Louis Jambou: "Músicas del siglo XVI en la obra de Manuel de Falla", Revista de Musicología, 27, 2, 2004, pp. 1050-1051 y 1054-1055; Carol A. Hess: Sacred Passions: The Life and Music of Manuel de Falla, Oxford, Oxford University Press, 2005, pp. 160-161; Nancy Lee Harper: Manuel de Falla: His Life and Music, Lanham, Scarecrow Press, 2005, 234-235. En contra de esta opinión prevaleciente, Elisa Rapado sostiene que el material temático de este movimiento es el mismo del primero y del tercero, la canción De los álamos vengo, madre, pero curiosamente al final de este texto la autora menciona que Maurice Ravel "valoraba sobre todo la inclusión del Pange Lingua More hispano en el segundo movimiento". E. Rapado: "El Concierto de Manuel de Falla", Filomusica, 20, 2001 (http://filomusica.com/ filo20/elirapa.html, consulta 24-6-2019).

${ }^{8}$ R. López Cano: Música dispersa..., p. 91.
} 
En el caso del material temático usado por Falla en el "Lento" de su Concerto, podría tratarse más bien de una cita expandida':"El material importado es usado compositivamente de manera orgánica para el crecimiento formal de, por lo menos, una buena parte de la nueva pieza".

Mientras que Britten acoge también la letra de la antífona en el comienzo y en el cierre de su obra, en las obras de Respighi y de Falla nos encontramos ante intertextos vocales, es decir, melodías que remiten a las letras y a sus significados, generando así redes de sentido en torno a las composiciones ${ }^{10}$.

En todos estos casos el material gregoriano citado es sometido a diferentes niveles de elaboración de acuerdo al idiolecto de cada compositor y a los propósitos concebidos para cada obra.Y esto es lo que tratamos de apreciar en el legado creativo del compositor chileno Alfonso Letelier Llona.

\section{Perfil de Alfonso Letelier Llona}

Según la tipología propuesta por Merino y Garrido ${ }^{11}$, Alfonso Letelier Llona (1912-1994) es un compositor que tuvo una vinculación mayor con la Universidad de Chile. Letelier estableció su relación con este organismo desde su etapa de formación como compositor, en la época en que Domingo Santa Cruz Wilson (1899-1987) lideró la implementación de una institucionalidad que fue gravitante para el cultivo de la música académica en Chile, especialmente en el ámbito del estímulo y difusión de la obra de compositores chilenos. Esto permitió la existencia de instituciones como la Facultad de Bellas Artes (a la que se incorporó el antiguo Conservatorio Nacional de Música y, posteriormente, escindida en Facultad de Ciencias y Artes Musicales y Facultad de Ciencias y Artes Plásticas), el Instituto de Extensión Musical (IEM), la Orquesta Sinfónica (Nacional) de Chile $(\mathrm{OSCH})$ y los Festivales de Música Chilena (FMCH), todas cobijadas por la Universidad de Chile.

\footnotetext{
${ }^{9}$ R. López Cano: Música dispersa..., p. 101. L. Jambou: "Músicas del siglo XVI...”, pp. 1054-1055 identifica solo al Pange lingua more hispano como material temático de esta pieza en términos de "motivo sumergido".

${ }^{10}$ R. López Cano: Música dispersa..., pp. 105-120. En el caso de la "Adoración de los Magos", la letra evocada por la melodía Veni, veni Emmanuel subraya el contexto de veneración al Cristo recién nacido en la pintura de Botticelli a la que remite el movimiento. Y en el "Lento" del Concerto de Falla, la remisión a las letras del Pange lingua o de la entonación salmódica se asocia con rituales, ceremonias y procesiones.

${ }^{11}$ Luis Merino Montero, Julio Garrido Letelier: "La crisis institucional de la Universidad de Chile y la circulación, preservación, recepción y valoración de la música sinfónica de los compositores chilenos: una propuesta teórico-metodológica", Resonancias, 42, 2018, pp. 79-113. Estos autores proponen cuatro categorías de vinculación de compositores con la institucionalidad de la Universidad de Chile: a) mayor, b) intermedia, c) menor y d) marginal.
} 
Letelier llegó a ser una de las personas de mayor cercanía y confianza para Santa Cruz, junto con Juan Orrego-Salas (n. 1919) y el musicólogo español Vicente Salas Viu (1911-1967), al punto que llegó a suceder a Santa Cruz en el cargo de decano de la Facultad de Ciencias y Artes Musicales (1952-1962). Más tarde fue galardonado con el Premio Nacional de Arte mención Música (1968) y, durante su trayectoria, estableció vínculos con instituciones internacionales como la Sociedad Internacional de Música Contemporánea (SIMC).

Luis Merino se refiere a Letelier como un compositor con "una profunda y sensitiva fe cristiana" 12 . De hecho, en oposición a las reformas litúrgicas que se implementaron en el seno de la iglesia católica romana como consecuencia del Concilio Vaticano II, Letelier participó en 1969 en la fundación de la Asociación Cultural de Artes Cristianas y Litúrgicas "Magnificat", cuya presidencia ejerció desde ese año hasta su muerte ${ }^{13}$. Sin embargo, su hijo Miguel Letelier Valdés dejó testimonio de que su padre tuvo "muchos peros, se cuestionó mucho y fue perdiendo la fe al final de su vida"

De las 62 obras en el catálogo oficial de Letelier, veintidós pueden calificarse como obras religiosas $(35,5 \%)$, once de ellas estrenadas y con circulación en Chile $(50 \%)^{15}$. Ahora bien, por "música religiosa" debe entenderse un espectro amplio que abarca desde piezas claramente vinculadas con la liturgia católica hasta otras cuyo texto corresponde a reflexiones de índole existencial y metafisica. Sin embargo, no solo la letra o el título de una obra sino otros factores, entre ellos evidencias en la estructura musical, pueden justificar su calificación como religiosa.

De lo dicho anteriormente deriva la importancia que tiene, como se mostrará a continuación, el uso intertextual del canto gregoriano en la música de Letelier. Tanto Jorge Urrutia ${ }^{16}$ como Julia Inés Grandela ${ }^{17}$ señalan la importancia que tiene este repertorio en la obra del compositor y mencionan, sin entrar en detalles, algunas piezas donde este rasgo es importante. Así, dentro de su producción religiosa, hay cuatro obras de Letelier que han sido destacadas por la crítica y la musicografía, Sonetos de la muerte (1942-1947),

\footnotetext{
${ }^{12}$ Luis Merino Montero: “Alfonso Letelier Llona (1912-1994) [Editorial]", Revista Musical Chilena (en adelante RMCH), 48, 182, 1994, p. 7.

${ }^{13}$ Julio Garrido Letelier: "La música litúrgica católica en el Concilio Vaticano II: aproximaciones al caso chileno", inédito, 2018.

${ }^{14}$ Hernán Gabriel Vázquez: Conversaciones en torno al CLAEM. Entrevistas a compositores becarios del Centro Latinoamericano de Altos Estudios Musicales, Instituto Nacional de Musicología Carlos Vega, Buenos Aires, 2015, p. 159.

${ }^{15}$ Las cifras y rangos de circulación se extraen de los datos registrados en $\mathrm{RMCH}$.

${ }^{16}$ Jorge Urrutia Blondel: "Los Sonetos de la muerte y otras obras sinfónicas de Alfonso Letelier", RMCH, 23, 109, 1968, p. 11.

${ }^{17}$ Julia Inés Grandela: "Letelier Llona, Alfonso", Diccionario de la música española e hispanoamericana, E. Casares Rodicio (ed.), vol. 6, Madrid, SGAE, 2000, p. 899.
} 
Vitrales de la Anunciación (1950), Sinfonía "El Hombre ante la Ciencia" (19831985) y Nocturno (1991). En ellas se enfocará este estudio, en el que se aplica el mismo marco para las cuatro obras: poiesis y circulación, recepción y uso intertextual del canto gregoriano. No es el objetivo presentar análisis detallados de cada obra abarcando a cabalidad aspectos como la armonización, la orquestación o la elaboración contrapuntística, sino enfocarse en los puntos indicados.

\section{Sonetos de la muerte, op. 18 (1942-1947)}

\section{Poiesis y circulación}

La obra Sonetos de la muerte fue definida por el compositor como un "poema dramático para orquesta y voz de mujer" con tres partes o movimientos, basados en los poemas homónimos de la escritora chilena Gabriela Mistral (1889-1957): "Del nicho helado", "Y este largo cansancio" y "Malas manos". Letelier dedicó esta obra a su madre, María Luisa Llona Reyes, "con quien mi música vive en deuda permanente"18.

Cada movimiento fue escrito y estrenado en distintos años durante la década de 1940. El n. ${ }^{\circ} 3$ ("Malas manos") fue estrenado el 26 de noviembre de 1948 en el Teatro Municipal de Santiago, en el marco del Primer Festival de Música Chilena, con Teresa Yrarrázaval (soprano) y la Orquesta Sinfónica de Chile bajo la dirección de Víctor Tevah. Los mismos artistas estrenaron la obra completa al año siguiente. Esta volvió a presentarse de forma íntegra en 1954 (Angélica Montes, OSCH, Tevah), 1966 (Montes, OSCH, Tevah), 1989 (Miryam Singer, OSCH,Volker Wangenheim) y 2011 (Carolina Muñoz, OSCH, Tobias Volkmann ${ }^{19}$. Además la versión de 1966 fue grabada en 1982 en el elepé Orión 83448.

\section{Recepción}

Con ocasión del estreno del Soneto de la muerte $n .^{\circ} 3$ ("Malas manos") en 1948, el crítico Daniel Quiroga emitió un comentario muy favorable al considerar que acusaba "una maduración estilística de indudable calidad y profundidad" 20 , al igual que en el estreno de la obra integral al año siguiente, donde afirmó que el tercer soneto era “quizá el más logrado de todos, en el que voz y orquesta logran unirse plenamente en un todo de

${ }^{18}$ Alfonso Letelier Llona: Sonetos de la muerte. Poema dramático para orquesta y voz de mujer con texto de Gabriela Mistral. Partitura manuscrita, 1947. Archivo Musical de la Facultad de Artes, Universidad de Chile.

${ }^{19} \mathrm{RMCH}, 4,32,1948-49$, p. $14 ; 5,35-36,1949$, p. $75 ; 47,1954$, p. $42 ; 20,97,1966$, p. $73 ; 43,172$, 1989, pp. 86-87; 66, 217, 2012, p. 107.

20 Daniel Quiroga Novoa: "Festivales de Música Chilena”, RMCH, 4, 32, 1948-49, p. 47. 
acentuado dramatismo, de austera y dolorida expresividad"21. En contraste, ese mismo año el crítico César Cecchi no valoró positivamente la obra en su presentación completa al estimar que no lograba "un equilibrio justo, verdadero y espontáneo entre los dos elementos [voz y orquesta]" y se inclinó hacia el Soneto n. ${ }^{\circ} 2$ como su preferido debido a su "íntimo acuerdo entre texto literario y música", juzgando inconveniente presentar los tres sonetos en un solo concierto $^{22}$. Años después, Federico Heinlein confirmaría la valoración positiva de Quiroga de la obra integral al afirmar que:

La angustia entrañable que late en estas páginas tremendas sobre los célebres versos de Gabriela Mistral convierten en experiencia emotiva poco menos que abrumadora la audición integral de la obra, que parece hablar el idioma de un alma en el colmo del desconsuelo, no obstante algunos rayos de inquieta esperanza. Especie de vasto poema sinfónico, con intervenciones vocales que dan al texto un tratamiento silábico, hay aquí un expresionismo de buena ley, que no deja de hacer impacto ${ }^{23}$.

Dos años después, el artículo de Urrutia refrendaría la aprobación generalizada hacia esta obra. Y a dichos textos debe agregarse uno del propio compositor al que haremos mención en la sección siguiente.

\section{Uso intertextual del canto gregoriano en la obra}

En el Soneto de la muerte $n .^{\circ} 3$ ("Malas manos") ${ }^{24}$, Letelier recurre a la antífona gregoriana Salve Regina. El mismo compositor lo expone en sus propias palabras $^{25}$ :

La Antífona "Salve Regina" es una bellísima monodia gregoriana de gran interés desde varios aspectos. Partiendo de su estructura interválica modal dórica, circunscrita a solo las cinco notas comprendidas entre Re y La (siendo ciertamente Re la nota llamada final), lo rotundo de este planteamiento debido a la fisonomía melódica del motivo inicial, su clara división en dos fragmentos rítmicos y melódicamente tan distintos y su sobriedad me parecieron condiciones de gran utilidad para una composición de compleja y extensa elaboración. Además el texto de este tercer soneto tiene una connotación religiosa.

Letelier también explica que a partir de las dos primeras frases de la antífona generó tres motivos. En el Ejemplo 1, adaptado del que aporta el propio compositor, se puede observar esta relación:

\footnotetext{
${ }^{21}$ D. Quiroga Novoa: "Conciertos", RMCH, 5, 35-36, 1948-49, p. 75.

${ }^{22}$ César Cecchi: "Crítica de Conciertos", Pro Arte, 1, 48, 1949, p. 3.

${ }^{23}$ Citado en "Crónica", RMCH, 20, 97, 1966, p. 73.

${ }^{24}$ Texto completo del poema en apéndice.

${ }^{25}$ A. Letelier Llona: "Los Sonetos de la muerte en su acontecer musical", RMCH, 35, 153-155, 1981, pp. 95-96.
} 


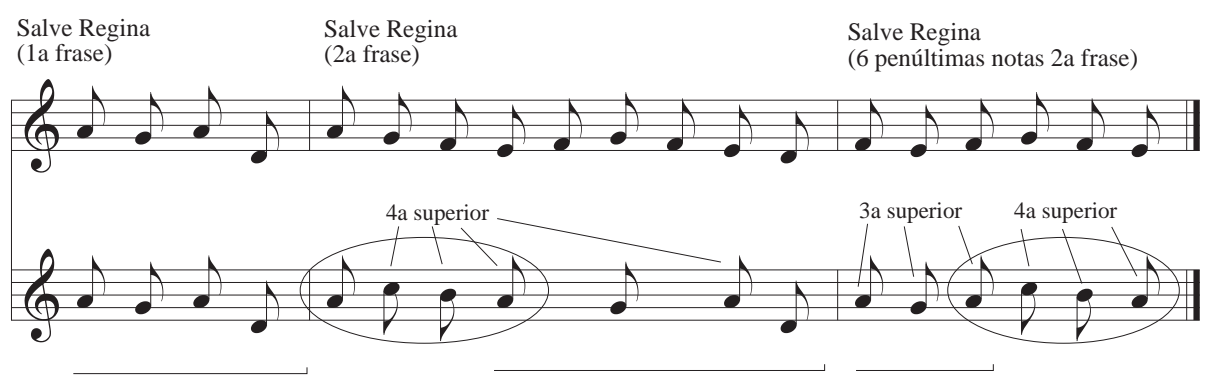

Ejemplo 1. Motivos del Soneto de la muerte n. ${ }^{\circ} 3$

En la pauta superior están las primeras dos frases del Salve Regina más las seis penúltimas notas de la segunda frase. En la pauta inferior están los tres motivos derivados indicando con palabras y líneas oblicuas los mecanismos de elaboración según Letelier. En el primer motivo se trata de la trasposición literal de la primera frase de la antífona. En el segundo las notas 2. ${ }^{a}, 3 .^{a}, 4 .^{a}$ y $8 .^{a}$ de la segunda frase son transportadas a la cuarta superior, se suprimen las notas $5 .^{a}$ y $7 .^{a}$ y se conserva la $6 .^{a}$. En el tercero, las primeras tres notas son transportadas una tercera superior y las tres siguientes una cuarta superior.

Sin embargo, los motivos 2 y 3 pueden explicarse también de otra manera, y esto se indica con el corchete debajo del motivo 1 y el óvalo que rodea las cuatro primeras notas del motivo 2 . El motivo 2 puede entenderse como conjunción entre esas primeras cuatro notas, derivadas de la elaboración que expone Letelier, y el mismo motivo 1. Mientras el motivo 3 se puede comprender casi como una conjunción de los mismos materiales del motivo 2, pero en orden inverso y con supresión de la última nota del motivo 1 (o bien, con alteración de esa última nota).

Estos tres motivos derivados del Salve Regina permean todo el tejido polifónico de la pieza, que presenta una gran complejidad armónico-tonal y densidad cromática en torno al eje de Si bemol, constituyendo así una cita expandida de la pieza gregoriana. Los tres motivos son presentados, transportados, variados y compartidos por distintos instrumentos de la orquesta, comenzando con el motivo 3 en las flautas (cc. 2-3), además de combinarse con material temático proveniente de los otros dos Sonetos.

La voz femenina, a cargo del texto lírico, expone una estructura melódica de desarrollo continuo donde en cuatro ocasiones presenta explícitamente alguno de estos motivos: con el texto "Malas manos tomaron tu vida" muestra el motivo 3 (cc. 30-32); con el texto "Malas manos entraron trágicamente" el motivo 1 (c. 75, precedido por el 3 en los cornos) y la indicación "Salmo" en la partitura; nuevamente el 3 con "No le puedo gritar" (cc. 117-119, mientras el 1 y 2 son expuestos por arpa y fagotes) y con "Que no tuve piedad" se alude otra vez al 1 (cc. 167-168). 
En esta obra, la melodía (no la letra) de la pieza gregoriana es el material temático fundamental y como dice el compositor, el texto del poema respalda esta decisión. En estos versos, la hablante lírica se dirige a Dios ("el Señor") suplicando por su amado y por sí misma. Por su parte, el texto de la antífona constituye un ruego de misericordia a laVirgen María, de modo que, aunque no sea incorporado de modo explícito o no se cite la melodía completa, se puede entender que el propósito del compositor fue subrayar el sentido de súplica a la divinidad, explícitamente a Dios en los versos de Mistral y tácitamente, a modo de intertexto vocal, a la Virgen María con la melodía gregoriana.

\section{Vitrales de la Anunciación, op. 20 (1950)}

\section{Poiesis y circulación}

Esta obra calificada como "cantata religiosa" está escrita para oboe, corno inglés, fagot, dos trompetas, piano, campanas, cuerdas, soprano y coro femenino. Tiene su origen en la música incidental de la pieza teatral La Anunciación hecha a María [L'Annonce faite à Marie] (1912) de Paul Claudel (18681955), estrenada y representada en Chile en $1949^{26}$. El compositor dedicó la obra a la memoria de su hermana Consuelo y por ello Gustavo Becerra Schmidt asevera que la obra "encierra sublimada toda la fuerza de su dolor, afecto y confianza en la determinación divina del acontecer humano" 27.

La obra, como pieza de concierto independiente de la obra teatral, fue estrenada el 31 de agosto de 1950 en el Salón Sur del Hotel Carrera en Santiago de Chile. Sus intérpretes fueron Clara Oyuela (soprano), las voces femeninas del Coro de Madrigalistas dirigido por Sylvia Soublette (concuñada del compositor), conjunto de cámara y la dirección general de Zoltan Fischer. Después de su estreno, existe registro de otras diez ejecuciones en Chile de esta obra, con diferentes intérpretes, entre 1950 y $2012^{28}$. Además

\footnotetext{
${ }^{26}$ Estrenada por el Teatro de Ensayo de la Universidad Católica de Chile. Letelier se vinculó con ella por la amistad que lo unía a Etienne Frois, Fernando Debesa y Pedro Mortheiru, quienes tradujeron y montaron la pieza.

${ }^{27}$ Gustavo Becerra Schmidt: "El Estilo de los Vitrales de la Anunciación Op. 20 de Alfonso Letelier", RMCH, 12, 57, 1958, p. 5. La muerte de Consuelo Letelier coincidió además con el estreno de la versión completa de los Sonetos de la muerte. Ver J. Urrutia: "Los Sonetos de la muerte...", p. 14.

${ }_{28}^{28 M C H}, 8,43$, 1952, pp. 89-90; 9, 44, 1954, p. 74; 17, 85, 1963, p. 123; 32, 142-144, 1978, p. 152; 42, 169, 1988, p. 104; 65, 215, 2011, p. 105; 66, 218, 2012, p. 114; folleto CD Alfonso Letelier: una luz del tiempo y del espacio (1996); información adicional en http://valarcondirector.blogspot.com/2013/01/ asd.html; http://pcdv.cl/web/wp-content/uploads/2013/08/Reseña-CFVM.pdf; www.ceacuchile. com/2012/07/maximiano-valdes-dirige-homenaje-de-la-orquesta-sinfonica-de-chile-a-alfonso-letelier/\#. W2CeZFAzbIU; www.uahurtado.cl/v-temporada-de-conciertos-presenta-alfonso-letelier-100-anos/ (consulta 31-7-2018).
} 
hay información de dos interpretaciones más de la obra en el extranjero ${ }^{29}$. Por otra parte, existe una edición de la partitura en $1976^{30}$ y tres registros fonográficos comerciales de ejecuciones en vivo de la obra ${ }^{31}$.

\section{Recepción}

Con ocasión del estreno de Vitrales, Daniel Quiroga escribió una reseña en la que destaca el "enlace entre la religiosidad fundamental que mueve la obra, y los generosos medios musicales [...] con que Letelier encara la armonía y la orquestación" ${ }^{2}$. En 1955 el mismo compositor, al comentar la visita que realizó a Claudel en 1952, afirmó que Vitrales era "la más íntima y la más querida de mis obras musicales" 33 .

En 1958, la Revista Musical Chilena, órgano nacido en el seno del Instituto de Extensión Musical, publicó el análisis de la obra hecho por Becerra ${ }^{34}$. Este autor aborda Vitrales como obra musical autónoma, incluso tomando el texto (letra) solo como referencia. De este modo, realiza un análisis sistemático dando cuenta de elementos melódicos, texturales, instrumentales y formales. Becerra identifica el vínculo estilístico de los Vitrales con el canto gregoriano y con la polifonía renacentista, pero también con la armonía moderna de cuño hindemithiano y aún con cierta tendencia al serialismo. Sin embargo, destaca especialmente la dimensión melódica de la obra.Años después Letelier endosó este estudio ${ }^{35}$.

En 1988, tras la presentación de la obra en mayo de 1987 en el Teatro Municipal de Santiago, el director Maximiliano Valdés afirmó que esta era "muy querida por él no solo por ser una obra muy inspirada escrita por su tío ${ }^{36}$, sino también porque su madre, Sylvia Soublette, la cantó en el estreno, dándole un sello muy particular" ${ }^{37}$. En 1997, al reseñar la aparición en CD de la obra, Guillermo Marchant propone un vínculo entre

${ }^{29} \mathrm{RMCH}, 9,47,1954$, p. $67 ; 11,55,1957$, p. 44. En RMCH, 42, 169, 1988, p. 104 se afirma que "la obra ha sido ejecutada en diversas oportunidades, tanto en Chile como en Argentina".

${ }^{30}$ A. Letelier Llona: Vitrales de la Anunciación, Letra de la liturgia católica de Adviento, Lope de Vega y Juan Álvarez Gato. Santiago de Chile, Facultad de Ciencias y Artes Musicales y de la Representación, 1976.

${ }^{31}$ Obras Sinfónicas/Vitrales de la Anunciación (elepé RCA Victor, CRL 2, 1953); Música Contemporánea. Alfonso Letelier Llona, compositor chileno (SVR MCC 04, 1988), fonograma reeditado como CD con el título Alfonso Letelier: Una luz del tiempo y del espacio (SVR-3006-2, 1996); Música Chilena, 15 años de Interpretación 1998-2012 (Facultad de Artes, DMUS, 2012, CD N. ${ }^{\circ}$ 6). Hay además una cuarta versión digitalizada: www.ceacuchile.com/multimedia/discografia/\#.W3m4tugzbIU.

${ }^{32} \mathrm{RMCH}, 6,38,1950$, p. 138.

${ }^{33}$ Alfonso Letelier Llona: "Mi visita a Paul Claudel", RMCH, 10, 49, 1955, p. 19.

${ }^{34}$ C. Cecchi: "Crítica de Conciertos...".

${ }^{35} \mathrm{RMCH}, 42,169,1988$, p. 104.

${ }^{36}$ Maximiliano Valdés es hijo de Sylvia Soublette y de Gabriel Valdés (político y músico aficionado), el cual era hermano de Margarita Valdés, la esposa de Letelier. Por tanto, Max Valdés es sobrino político del compositor.

${ }^{37} \mathrm{RMCH}, 42,169,1988$, pp. 103-104. 
los fragmentos litúrgicos, el concepto de "vitral gótico" y los juegos de textura musical ${ }^{38}$.Y en 2000 Grandela la califica como su obra cumbre en la música religiosa ${ }^{39}$.

\section{Uso intertextual del canto gregoriano en la obra}

Vitrales de la Anunciación presenta cinco partes o "vitrales" que ocupan textos en latín y en castellano:

Vitral I: "El ángel del Señor anunció a María (Lento, versículo I del Angelus)" Regina coeli laetare.

Vitral II: "He aquí la esclava del Señor (versículo II del Angelus)".

Vitral III:"Alma dormida despierta (Muy tranquilo-Allegro molto [Forlana]-Tempo I, villancico a la Virgen sobre un poema de Lope de Vega)".

Vitral IV: "Venida es al mundo la vida (Moderado, villancico sobre un poema de Lope de Vega)" - "Sabed que una virgen concebirá" (Más lento, profecía de Isaías) - Rorate caeli desuper.

VitralV:"Y elVerbo se hizo carne (Lento, versículo III del Angelus)" - "Oh clara Virginidad (Más movido, villancico sobre un poema de Álvarez del Gato)".

Esta obra puede calificarse como transición entre una tonalidad expandida y una "atonalidad" que se acerca al serialismo, como dice Becerra ${ }^{40}$. En ella encontramos regiones claramente tonales, como ocurre en los Vitrales I y IV donde Letelier integra las piezas gregorianas Regina coeli laetare y Rorate caeli desuper, respectivamente, tanto letra como melodía.

El Vitral I comienza con una sección instrumental titulada "Organum Cuadruplum" (cc.1-39) pero que corresponde más bien a una fuga. A continuación, una sección (Tiempo I meno mosso) donde entra la voz con el texto "El Ángel del Señor anunció a María” y se retoma el "organum" (cc. 40-63). En el c. 63 comienza la última sección con el canto Regina coeli laetare en el tono de $\mathrm{Fa}$, con un tratamiento que presenta alternancia entre unísonos y texturas acórdicas que evocan parcialmente la técnica del organum primitivo medieval, como se observa en el Ejemplo $2^{41}$.

El canto aparece al unísono en los compases 63 y 64, para ser posteriormente armonizado a cuatro voces en el compás 65. Esta armonización no es convencional, dado el uso de cromatismos en las líneas melódicas y cuartas paralelas que expanden la tonalidad. En el compás 66 la textura se reduce a dos voces y retorna al unísono, para pasar en el compás 67 a un organum de quintas paralelas duplicadas que, luego de un fugaz paso por una

\footnotetext{
${ }^{38} \mathrm{RMCH}, 51,188,1997$, p. 118.

39 J. I. Grandela: "Letelier Llona, Alfonso", p. 897.

${ }^{40}$ G. Becerra Schmidt: "El estilo de los Vitrales...", p. 10.

${ }^{41}$ Todas las transcripciones fueron hechas por el autor de este artículo a partir de las copias o ejemplares disponibles de las partituras.
} 
armonización a tres voces, desemboca en un unísono duplicado en el c. 68 y termina nuevamente con un unísono cabal en el c. 69. En estos siete compases además las voces son acompañadas por las cuerdas, que discretamente duplican alternadamente a alguna de las líneas de las sopranos o de las altos. De este modo, si bien el canto concluye en el tono de Fa, la armonización provista por las cuerdas cierra en la tonalidad paralela de Re menor.

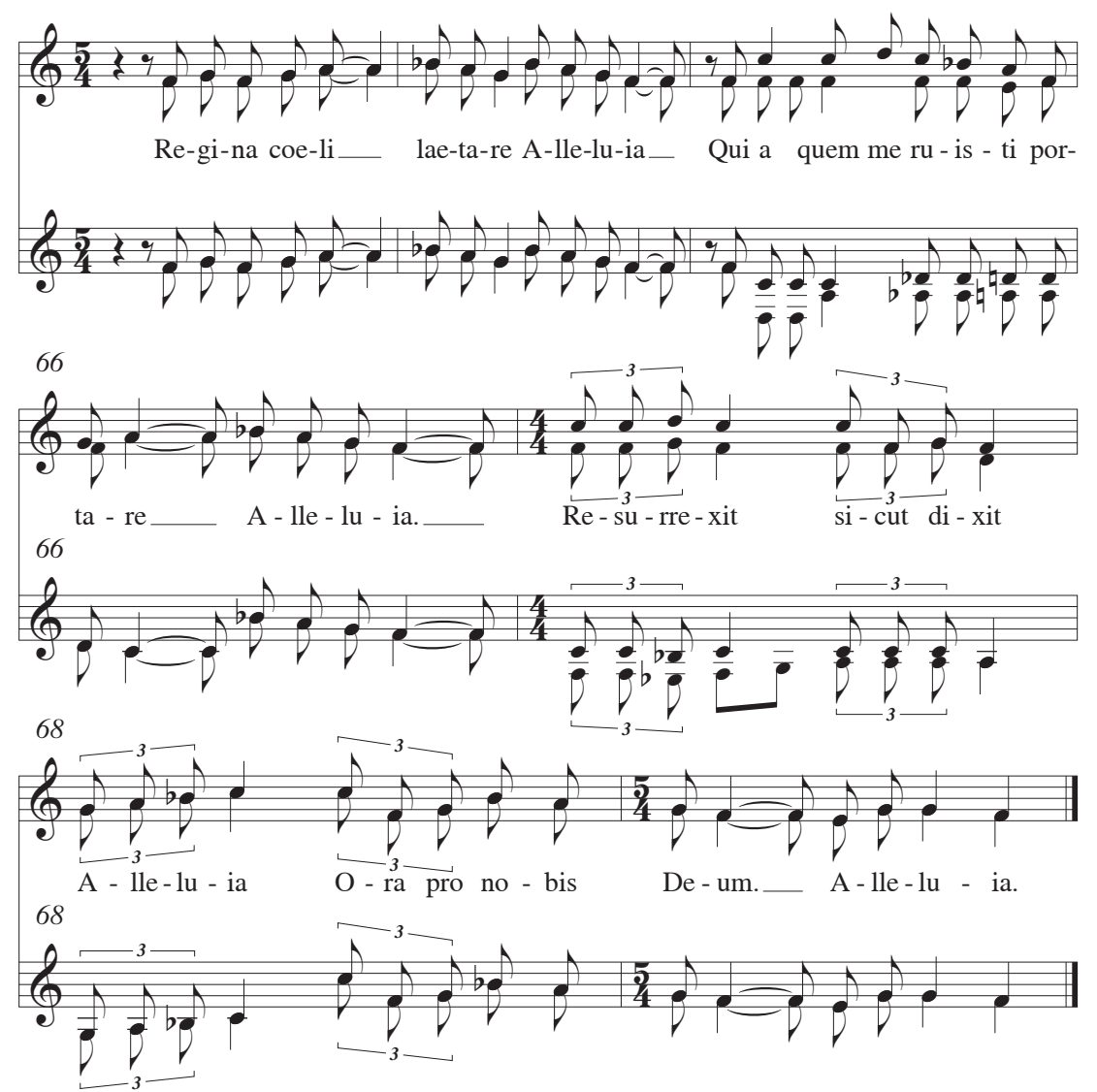

Ejemplo 2. Vitrales de la Anunciación I, Regina coeli (solo voces, cc. 63-69)

La incorporación del Regina coeli laetare corresponde a una cita parentética, pero habría que agregar que se trata de una cita variada por la elaboración armónica y textural a la que se somete ${ }^{42}$. Hay que señalar además, antes de pasar alVitral IV, que Letelier no incorporó el texto completo del Regina

\footnotetext{
${ }^{42}$ En términos estrictos, casi toda cita parentética presenta algún grado de variación melódica, armónica, textural o tímbrico/instrumental.
} 
coeli laetare, ya que omitió los dos versos finales (indicados a continuación entre corchetes):

Regina caeli, laetare, alleluia.

Quia quem meruisti portare, alleluia.

Resurrexit, sicut dixit, alleluia.

Ora pro nobis Deum, alleluia.

[Gaude et laetare Virgo Maria, alleluia.

Quia surrexit Dominus vere, alleluia $]^{43}$.

ElVitral IV consiste en una sección instrumental (cc. 1-21), el canto de un texto de Lope de Vega, "Venida es, venida al mundo la vida" (cc. 22-39), una nueva sección instrumental (cc. 40-64), el canto del texto bíblico de Isaías "Sabed que una Virgen" (cc. 65-70), otra sección instrumental (cc. 71-84) y el canto Rorate caeli desuper (cc. 84-110). El texto de este último es el siguiente:

Rorate caeli desuper, et nubes pluant justum

Consolamini, consolamini, popule meus:

Cito veniet salus tua

Aperiatur terra, et germinet Salvatorem ${ }^{44}$.

Es interesante que este texto resulta de una combinación hecha por Letelier de dos versiones litúrgicas del mismo canto, el que es propio de la época de Adviento. El verso "Rorate caeli desuper, et nubes pluant justum" funciona como primera parte de la antífona del introito en la misa del cuarto domingo de Adviento, pero también como antífona del canto de bendición del Santísimo Sacramento en el mismo período litúrgico. El versículo "Consolamini" es el cuarto de dicho canto de bendición, mientras "Aperiatur terra" es la segunda parte de la antífona del introito mencionado.

En otras palabras, Letelier insertó el cuarto versículo del canto de bendición entre las dos mitades de la antífona del introito. De este modo, probablemente buscó destacar que el mismo Cristo anunciado y esperado en Adviento es aquel cuyo sacrificio redentor es evocado en el sacramento de la eucaristía. Asimismo, desde el punto de vista melódico el compositor tomó como referencia tanto el canto de bendición como el introito, como se observa en los siguientes ejemplos $(3 \text {, } 4 \mathrm{a} \text { y } 4 \mathrm{~b})^{45}$.

43 "Reina del cielo, alégrate, aleluya / Porque el Señor, a quien has llevado en tu vientre, aleluya / Ha resucitado según su palabra, aleluya / Ruega al Señor por nosotros, aleluya / Goza y alégrate Virgen María, aleluya / Porque en verdad ha resucitado el Señor, aleluya".

44 "Derramad, oh cielos, vuestro rocío de lo alto, y las nubes lluevan al Justo / Consuélate, consuélate, pueblo mío ¡En breve ha de llegar tu salvación! / Ábrete, oh tierra, y germine la salvación”.

${ }^{45}$ Todos los ejemplos de canto gregoriano presentados corresponden a transcripciones de notación cuadrada a notación moderna hechas por el autor a partir de las mismas piezas tal como aparecen en la edición de 1961 del Liber Usualis. Habría que realizar una investigación más profunda para determinar cuáles pudieron ser las fuentes gregorianas originales que Letelier usó para su labor creadora. 
A ntífona del introito en misa del $4 .^{\circ}$ domingo de A dviento ( $1^{\text {a }}$ parte)

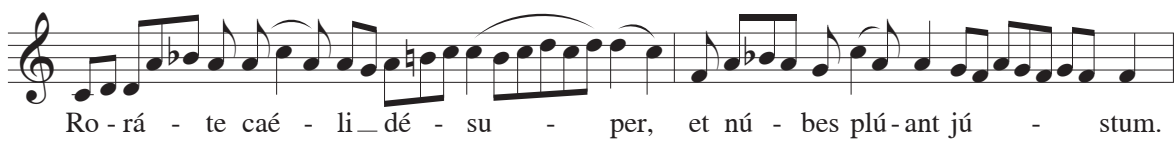

A ntífona del canto de bendición del Santísimo Sacramento en A dviento

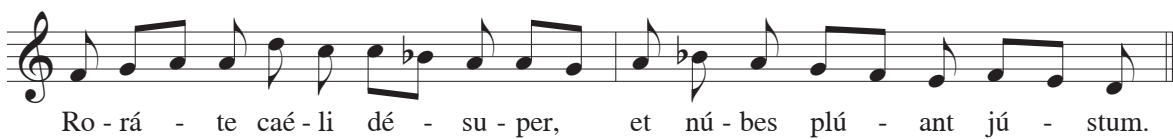

Versícul $04 .^{\circ}$ del canto de bendición del SS en A dviento

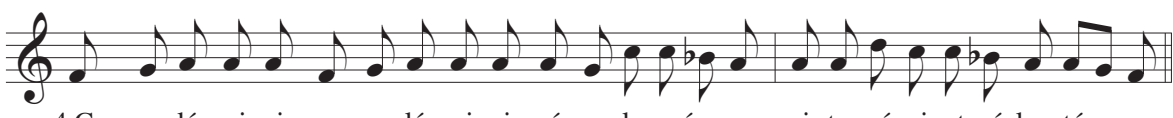

4.Con-so-lá-mi-ni, con-so-lá-mi-ni, pó-pu-le mé - us: ci-to vé-ni-et sá-lus tú - a.

A ntífona del introito en misa del $4 .^{\circ}$ domingo de A dviento ( $2^{\mathrm{a}}$ parte)

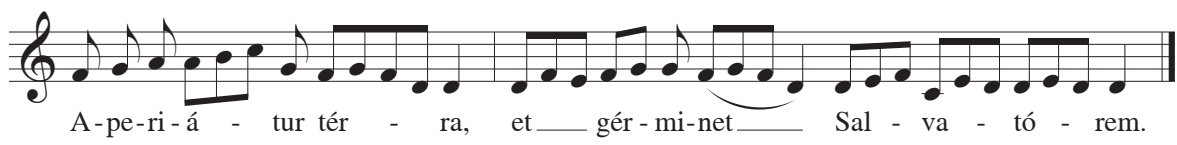

Ejemplo 3. Fragmentos del introito y canto de bendición Rorate caeli

Al hacer la comparación se aprecia que Letelier tomó principalmente la melodía del canto de bendición, la que sometió a elaboraciones interválicas, tonales y texturales. En los compases 84-89 la melodía principal se basa en la del canto de bendición y se armoniza a cuatro voces (con acordes extendidos), además de un sutil acompañamiento instrumental. Sin embargo, mientras los primeros dos compases (84-85, "Rorate") están en el tono de La menor, los siguientes (85-89) están en Do sostenido menor ${ }^{46}$. Después de un nexo instrumental (cc.90-91), el versículo "Consolamini" es cantado a partir de la melodía del canto de bendición, sometida a variaciones interválicas en el tono de Fa sostenido frigio (cc. 9294) y de Si menor (cc. 95-96).

${ }^{46}$ Para la determinación de tonos y modos, tomo en cuenta las alturas en cada agrupación de compases, la direccionalidad de los motivos melódicos (con énfasis en soprano y bajo) y notas de reposo (a menudo con duración algo más larga). 

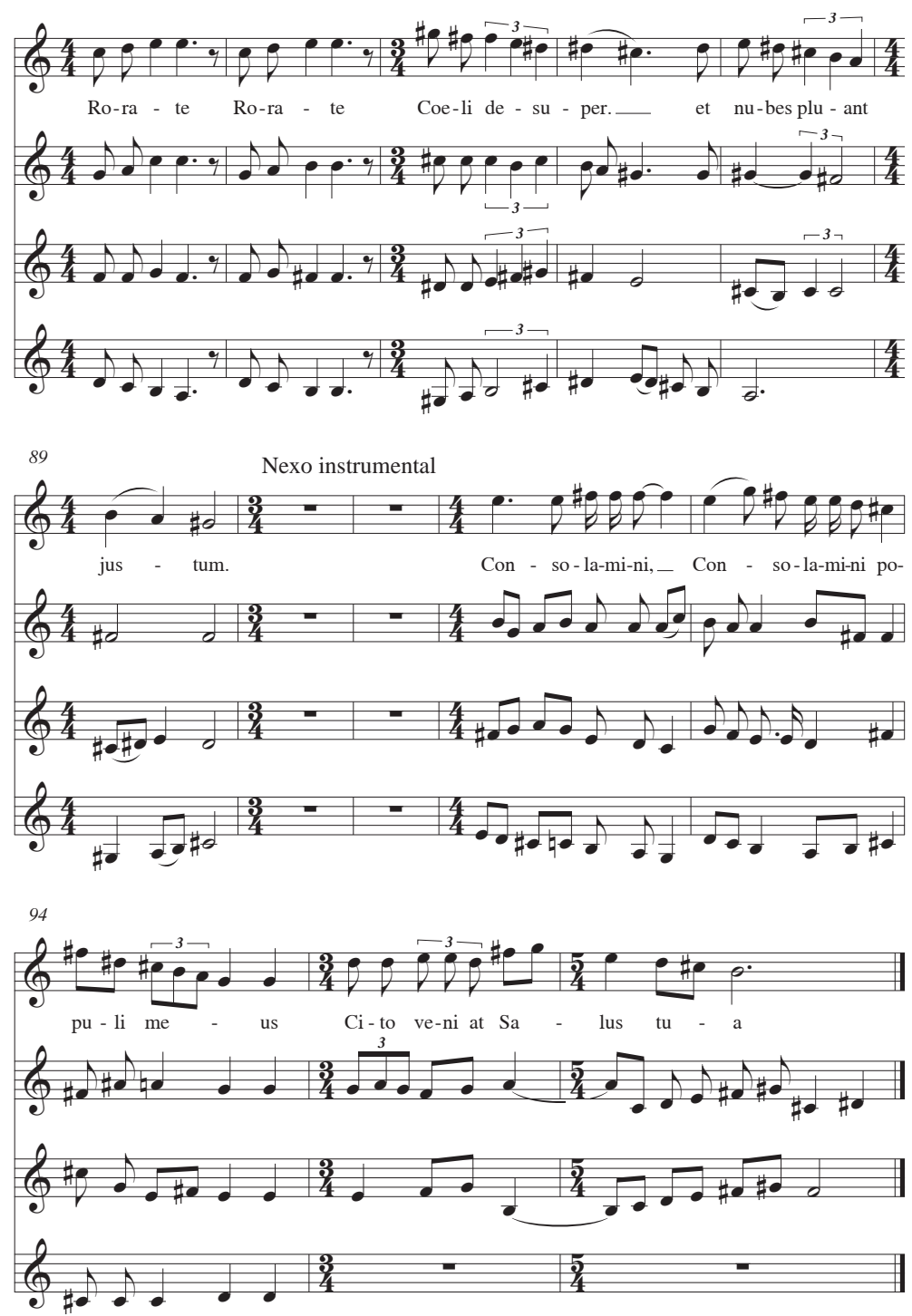

Ejemplo 4a. Vitrales de la Anunciación IV, Rorate coeli (solo voces, cc. 84-96)

Luego de otro nexo instrumental (cc. 97-98), las sopranos 2 y altos 1 presentan en imitación (cc. 99-103) el tema de "Rorate caeli desuper" en el tono de Do sostenido menor (con una entrada falsa adicional de las sopranos 1), siempre en base a la melodía del canto de bendición. Finalmente, luego de un último nexo instrumental (c. 104), se presenta el verso "Aperiatur terra" con su melodía principal basada en aquella del introito en el tono 
de Mi menor (cc. 105-106), mientras que en el verso "Et germinet Salvatorem" la melodía gregoriana parece traspasarse de sopranos 1 (c. 107) a altos 2 (cc. 108-110) para cadenciar en una quinta abierta Do sostenido -Sol sostenido en las sopranos, superpuesta a su inversión en armónica La bemol-, Re bemol en las altos (Ejemplo 4b).
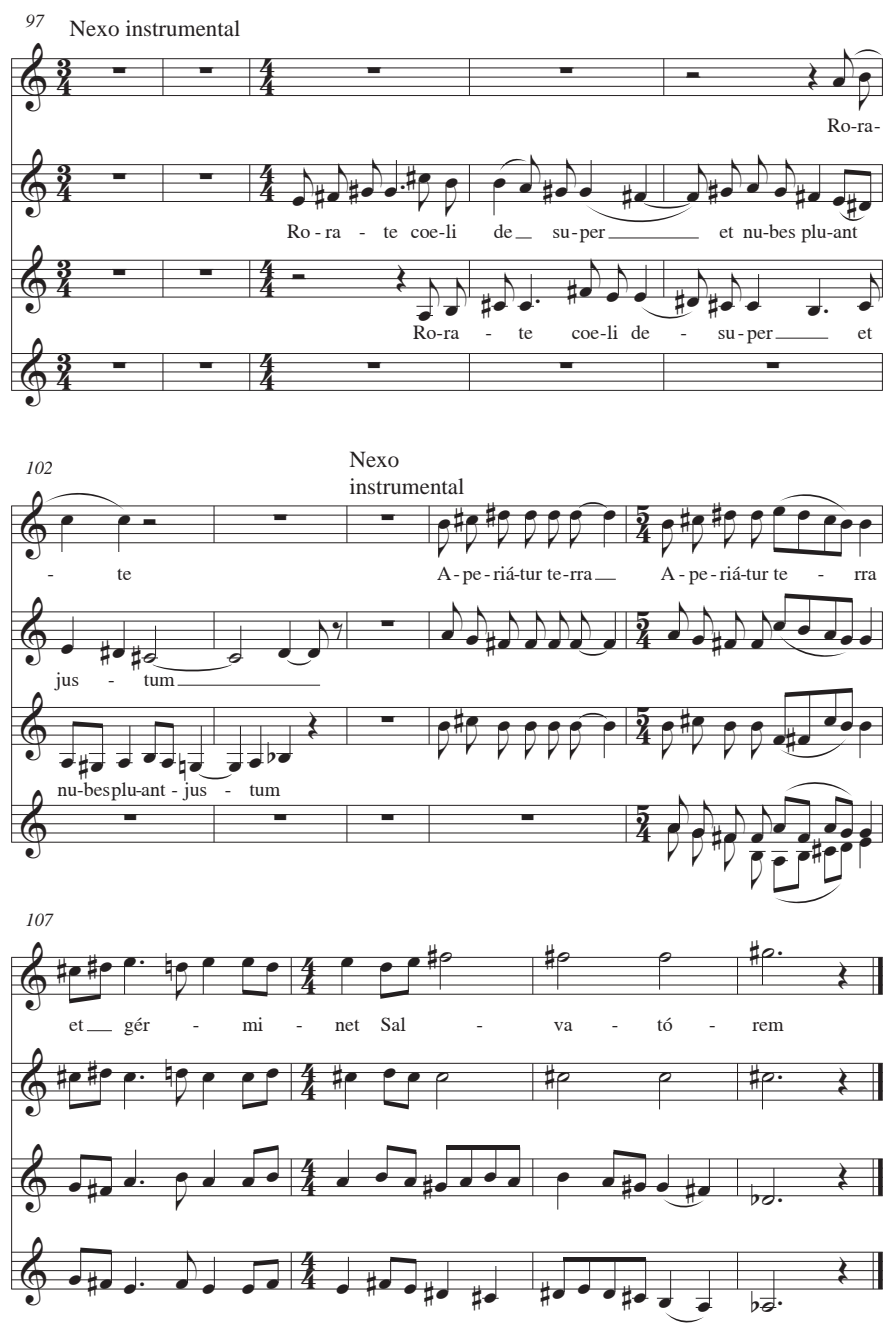

Ejemplo 4b: Vitrales de la Anunciación IV, Rorate coeli (solo voces, cc. 97-110)

Al ordenar en sucesión ascendente los diferentes tonos identificados en toda esta sección (La-Si-Do\#/Reb-Mi-Fa\#), podemos descubrir que, al permutar la posición de los dos últimos tonos (La-Si-Do\#-Fa\#-Mi), 
tenemos un transporte exacto de las cinco primeras notas del canto de bendición (Fa-Sol-La-Re-Do, Ejemplo 3). Por tanto, la melodía gregoriana no solo funciona como material melódico sino como base del plan tonal de la sección $^{47}$. De esta manera, la presencia del Rorate caeli desuper corresponde también a una cita parentética variada, pero sujeta en este caso a una mayor elaboración que afecta a diferentes niveles de la estructura musical.

El uso de estas dos piezas gregorianas en Vitrales de la Anunciación se explica por su relación directa con la temática de aquella obra teatral cuya puesta en música generó la composición de la obra. Al incorporarlas, Letelier subrayó ese carácter evocativo de atemporalidad que representan los vitrales de las iglesias medievales, acentuado con el uso de giros modales y de procedimientos polifónicos como el organum. Sin embargo, la complejidad de su elaboración melódica, armónica y tonal nos recuerda además, aunque en menor grado, aquella de los Sonetos de la muerte y de las siguientes dos obras que tomaremos en cuenta.

\section{Sinfonía "El Hombre ante la Ciencia” (1983-1985) \\ Poiesis y circulación}

Esta obra fue escrita para voz femenina solista y orquesta sinfónica entre 1983 y 1985. En una entrevista que Sonia Quintana le hizo al compositor en 1984, se da testimonio de que en su máquina de escribir estaba "una de las páginas de su próxima sinfonía, que ya tituló El Hombre ante la Ciencia 48 ". En ella confluyen distintos intereses de Letelier no solo musicales, sino además cosmológicos y existenciales, vinculados con su devoción hacia la naturaleza y los avances científicos ${ }^{49}$.

La Sinfonía "El Hombre ante la Ciencia" fue estrenada en 1987 por la contralto Carmen Luisa LetelierValdés, hija del compositor, y la OSCH bajo la dirección de Francisco Rettig Oyarzún. Después de su estreno no ha vuelto a ser ejecutada en Chile y su única interpretación hasta ahora quedó plasmada en un fonograma comercial que circuló primero como casete y después reeditado como $\mathrm{CD}^{50}$ : La obra tiene tres movimientos titulados "Azar", "Entropía" y

${ }^{47}$ En relación a esto, Becerra ("El estilo de los Vitrales...", p. 15) solo se limita a señalar que esta sección de la pieza "presenta un ejemplo melódico de modulación a base de giros gregorianos".

${ }^{48}$ Juan Pablo González, José Miguel Varas Morel: En busca de la música chilena. Crónica y antología de una historia sonora, Santiago, Catalonia, 2011, p. 365.

${ }^{49}$ Más detalles acerca de los intereses científicos de Letelier en https://patrimonio.cl/archivo/violeta-y-los-letelier/ (consulta 4-2-2019]. Erróneamente se califica aquí a la Sinfonía "El Hombre ante la Ciencia" como "obra póstuma".

${ }^{50}$ Casete Música Contemporánea. Alfonso Letelier Llona, compositor chileno (SVR MCC 04, 1988) y CD Alfonso Letelier: Una luz del tiempo y del espacio (SVR-3006-2, 1996). En el mismo fonograma está grabada una versión de Vitrales de la Anunciación. 
"Fe", y en el último de ellos se integra un poema escrito por el propio Lete$\operatorname{lier}^{51}$. Acerca de la razón de este texto comenta Carlos Riesco52: "según nos explicó, Alfonso Letelier buscó expresar a fe de bueno, como ya lo hemos mencionado con anterioridad, la profunda emoción que le producen los fenómenos de orden cósmico estudiados por intermedio de las disciplinas relacionadas con las diferentes ciencias. Debido a que no encontró poesía alguna que satisficiera su inquietud, optó por escribir, él mismo, el texto de un poema que sirviera de base a la estructura de la parte final de la Sinfonía”.

\section{Recepción}

Esta obra ha sido considerada como una de las cumbres en el legado creativo de Letelier. Así lo señala Riesco:

La última obra compuesta por Alfonso Letelier, Sinfonía “El hombre ante la ciencia", marca un hito de suma importancia en la creación musical chilena. En ella se deslumbra un lenguaje novedoso y diferente al que ya conocemos como característico de la música nuestra. Destacamos, entre muchas cualidades, un fácil manejo de las técnicas contemporáneas, que el compositor hace suyas, adaptándolas a las necesidades que requiere para dar vida a su expresión y, lo que consideramos aún más importante, cómo se fija espacios de orden cósmico desde el momento mismo que decide fraguar su impulso creador, al calor de la profunda emoción espiritual que le produce el conocimiento de las ciencias fisicas y matemáticas ${ }^{53}$.

En la dimensión estructural, Riesco destaca la generación del discurso musical a partir de un núcleo melódico constituido por semitono descendente-tono ascendente, el cual funciona como eje de elaboración temática a lo largo de los tres movimientos.

\section{Uso intertextual del canto gregoriano en la obra}

En su presentación de la obra, Riesco explicita el uso de una pieza gregoriana en el tercer movimiento ("Fe"):

Al tiempo que el texto llega a su término expresando

Bendita sea, Espacio-Tiempo

la agitación de tu hondura

porque una Presencia en tu seno

trocó el acaso por destino

desde algunos compases antes Letelier introduce el "Alleluia" gregoriano correspondiente al Domingo del Pentecostés ${ }^{54}$.

\footnotetext{
${ }^{51}$ Texto completo en apéndice.

${ }^{52}$ Carlos Riesco: "Sinfonía 'El Hombre ante la Ciencia”", Revista Musical Chilena, 42, 170, 1988, p. 80.

${ }^{53}$ Ibid., p. 75 .

${ }^{54}$ Ibid., pp. 84-85.
} 
Se trata del Alleluia veni Sancte Spiritus, efectivamente una pieza que pertenece a la liturgia del domingo de Pentecostés. Como en el caso del Salve Regina en el Soneto de la muerte $n .^{\circ} 3$, la letra no está incorporada dentro del discurso musical, pero en la partitura el compositor se encarga de plasmar el fragmento respectivo en una pauta auxiliar. De este modo, queda claro que Letelier quiso develar la procedencia de este material. Pero a diferencia del Soneto, en este caso la cita y elaboración de la pieza gregoriana aparecen en la sección final del movimiento, el cual posee, dentro de su complejidad tonal, un esquema que se aproxima al plan sonata.

El compositor escogió cuatro frases del canto original. Las primeras tres corresponden a la antífona ("Alleluia") y la cuarta procede del versículo, específicamente del texto "Et tui amoris", como se observa en la siguiente figura (Ejemplo 5):

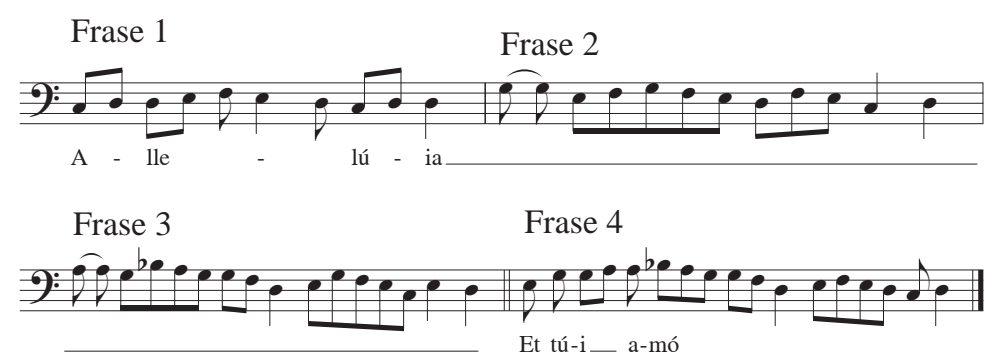

Ejemplo 5. Frases del Alleluia veni Sancte Spiritus

En medio de la trama orquestal, estas frases son distribuidas, con distintos grados de variación, de la siguiente manera entre maderas y cuerdas:

Frase 1: oboe 1 + violoncelo 1 (cc. 205-207)

Frase 2: oboe 1 (cc. 208-209)

Frase 1: violas (cc. 208-209)

Frase 4: corno inglés + violas (cc. 210-212)

Frase 1: clarinete bajo (cc. 219-220)

Frase 2: oboes (cc. 221-223)

Frase 3: corno inglés (cc. 225-227)

Tal como afirma Riesco, la presentación de estas frases entre los compases 205 y 212 anteceden la entrada de la cantante, la que entona el texto ya señalado, el que corresponde a la última estrofa del poema escrito por Letelier. Si bien el canto mismo no remite a ninguna de estas frases de manera literal, a partir del compás 219 las frases del Alleluia veni Sancte Spiritus forman parte del contrapunto al canto y no solo son citas parentéticas, sino que funcionan como intertexto vocal al remitir, sin explicitarla, a la letra de este canto. Esto conduce a postular que, para Letelier, la "Presencia" que habita 
en el seno del Espacio-Tiempo de la que habla el texto debe identificarse con el Espíritu Santo al que cantan los versos gregorianos. Incluso se podría decir que lo que Letelier ha escrito en toda esta sección final y, tal vez en toda la sinfonía, es la reinterpretación puesta en música del segundo versículo del Génesis:

La tierra ["Espacio-Tiempo"] era un caos total ["Azar"], las tinieblas cubrían el abismo ["Entropía"], y el Espíritu de Dios ["Presencia"] se movía sobre la superficie de las aguas ["Fe"]

\section{Nocturno (1991)}

Poiesis y circulación

Nocturno es una obra vocal ${ }^{56}$ dedicada al Ensemble Bartók-Chile, agrupación de la que formaba parte Carmen Luisa Letelier. Está escrita para voz, clarinete en Si bemol, violín, violoncelo y piano. El texto fue escrito, tal como ocurre con el último movimiento de la Sinfonía "El Hombre ante la Ciencia", por el propio compositor ${ }^{57}$. Este texto culmina con la cita (alterada en su final) de dos versos tomados del libro de las Lamentaciones de Jeremías $(1: 12)$ y usado con distintas melodías para diferentes ocasiones litúrgicas: "O vos omnes qui transitis per viam, attendite et videte: Si est dolor sicut dolor meus [el texto de Letelier dice "mundi"]" 58 .

No existe mucha información acerca de la gestación de esta pieza, la última del catálogo de Letelier. Si se considera esa crisis de fe que vivió el compositor en sus últimos años según el testimonio de su hijo Miguel, se podría vincular con la enfermedad y fallecimiento de Francisco Letelier Valdés, su hijo menor, en 1992. En todo caso, Letelier otorgaba una gran relevancia a esta pieza, de acuerdo a Valene Georges, clarinetista y fundadora del Ensemble Bartók-Chile:

Ha sido un privilegio para el Ensemble Bartók estar asociados a tantos compositores ilustres de Chile, empezando con nuestro padre espiritual, Don Alfonso Letelier, quien trabajó muchos años con nosotros compartiendo su sabiduría musical y regalándonos hacia el fin de su vida su última obra, Nocturno, que es una especie de compendio de su

${ }^{55}$ Nueva Versión Internacional de la Biblia, Miami, Editorial Bíblica (Sociedad Bíblica Internacional), 2015 .

${ }^{56}$ No debe confundirse con una pieza del mismo nombre, con texto de Carmen Valle, escrita para voz y cuarteto de cuerdas y que forma parte del ciclo Estancias Amorosas (1966) de Letelier.

${ }^{57}$ Texto completo en apéndice.

58 "iOh vosotros cuantos pasáis por el camino! mirad y ved si hay dolor comparable a mi dolor". Con la alteración en el texto de Letelier, la frase final "a mi dolor" es sustituida por "al dolor del mundo". 
pensamiento musical. Cómo olvidar su último pedido en su lecho de muerte, con mis manos entre las suyas, suplicándome "no dejen de cantar mi canción". Para nosotros es un ruego simbólico que incluye a toda la música chilena ${ }^{59}$.

Nocturno fue estrenado el 23 de octubre de 1991 en el Goethe-Institut de Santiago por el Ensemble Bartók-Chile. Todos los registros posteriores de sus ejecuciones, tanto en Chile como en el extranjero, corresponden a presentaciones de esta agrupación. En Chile tenemos dieciséis registros entre 1991 y 2012 , incluyendo su estreno ${ }^{60}$, y siete registros de presentaciones en el extranjero entre 1992 y $2005^{61}$.

Hasta hoy la partitura de la obra no ha sido publicada y el único registro comercial existente corresponde al CD Chile Contemporáneo en el sonido de Ensemble Bartok (SVR-6003-2, 1997), tomado de una presentación de la agrupación realizada en noviembre de 1996.

\section{Recepción}

Nocturno es una pieza que hasta ahora no ha sido objeto de análisis más o menos pormenorizados, ni de comentarios valorativos con la misma abundancia y elaboración que en el caso de las otras tres obras de Letelier que hemos considerado aquí. Con ocasión de su estreno, Quiroga escribió que "el compositor chileno que parece sentir una agobiante angustia existencial, lo dice en música con vigorosa entrega de concentrados medios expresivos. El auditorio podía recordar los mejores momentos de los Sonetos de la muerte del autor" ${ }^{2}$. Casi las mismas palabras reiteran Fernando García $^{63}$ y Marchant ${ }^{64}$. Por su parte, Grandela señala su lugar como última pieza del compositor y su "inspiración" en el $O$ vos omnes ${ }^{65}$.

Un sucinto pero interesante comentario fue escrito por el crítico estadounidense Allan Kozinn, publicado con ocasión de la presentación que realizó el Ensemble Bartók-Chile en la Sala Weill del Carnegie Hall el 29 de septiembre

\footnotetext{
${ }^{59}$ RMCH, 53, 191, 1999, p. 88.

${ }^{60} \mathrm{RMCH}, 45,176,1991$, p. 109; 46, 178, 1992, pp. 115, 116; 48, 181, 1994, p. 130; 48, 182, 1994, p. $128 ; 49,183,1995$, pp. $107,109,117 ; 50,186,1996$, pp. $87,88,93 ; 52,189$, 1998, p. $95 ; 54,194$, 2000, p. 102; 59, 204, 2005, p. 113; 66, 217, 2012, pp. 107-108; folleto del CD Chile Contemporáneo en el sonido de Ensemble Bartók.

${ }^{61} \mathrm{RMCH}, 46,178,1992$, p. 115, 116; 47, 179, 1993, p. 135; 50, 186, 1996, p. 93; 52, 189, 1998, p. $89 ; 54,193,2000$, p. 100; 55, 195, 2001, p. 85; 59, 204, 2005, p. 117.

${ }^{62}$ D. Quiroga Novoa: "Crítica musical”, El Mercurio, 33014, 26-10-1991, cuerpo C, p. 6.

${ }^{63} \mathrm{RMCH}, 45,176,1991$, p. 109.

${ }^{64}$ RMCH, 53, 189, 1998, pp. 105-106.

${ }^{65}$ J. I. Grandela: "Letelier Llona, Alfonso", p. 899.
} 
de 1992:"Nocturno (1991) de Alfonso Letelier establece un clima oscuro y nerviosamente intenso del cual emergían melodías elegantes y cálidas" ${ }^{.}$.

Estas palabras se pueden relacionar con aquellas que enuncia Georges ya citadas, "es una especie de compendio de su pensamiento musical". Un compendio que se entrevera con un texto que devela "una agobiante angustia existencial" y que culmina, como se verá a continuación, no solo con la cita de un texto sino de una melodía gregoriana cuidadosamente transformada.

\section{Uso intertextual del canto gregoriano en la obra}

Nocturno es una pieza disonante, pero no completamente "atonal", ya que se percibe un eje en torno a los tonos de $\mathrm{Re}$ y $\mathrm{Si}$ bemol ${ }^{67}$. Al respecto, resulta interesante notar que la versión gregoriana de $O$ vos omnes usada para la fiesta de la Virgen de los Dolores (15 de septiembre), correspondiente en este caso a un versículo del Alleluia, se encuentra en el modo II ("hipodorio"), donde $\mathrm{Re}$ es la nota principal o finalis ${ }^{68}$. Al observar con atención la estructura melódica de esta versión de $\mathrm{O}$ vos omnes se detectan ciertas coincidencias que permiten postular que Letelier elaboró esta estructura para poner en música el mismo texto ${ }^{69}$ en los últimos compases (85-100) de su obra, como se aprecia en los Ejemplos 6a-6b:

Bajo este supuesto, la estrategia de Letelier fue llevar a cabo una fragmentación de la melodía original mediante la sustracción de elementos de cada segmento correspondiente a cada verso o frase del canto litúrgico, añadiendo variaciones melódicas o interválicas, generando una sucesión melódica tonalmente inestable y manteniendo el mismo texto, con excepción del cambio introducido en la última palabra.Así, para la frase 1 "O vos omnes” tomó las primeras tres notas ( $\mathrm{Fa}, \mathrm{Sol}, \mathrm{La}$, en corchete) de la pieza gregoriana y el marco interválico de tercera menor descendente (en óvalo). En la frase 2 "Qui transitis per viam" consideró las terceras descendentes y el giro ascen-

66 "Alfonso Letelier's Nocturno (1991) establishes a dark, edgily intense mood from which graceful, warmly couched melodies emerged". Allan Kozinn: "Classical Music in Review", The New York Times (1-10-1992), p. 14 (https://www.nytimes.com/1992/10/01/arts/classical-music-in-review-534692.html, consulta 1-8-2018).

${ }^{67}$ De modo similar a la identificación de modos en los trozos de Vitrales de la Anunciación, postulo estos ejes tonales tomando en cuenta la dirección de giros melódicos y especialmente las notas de reposo en el canto o en los instrumentos, con énfasis en el piano.

${ }^{68}$ En este caso la indicación del modo está dada en la versión que aparece en el Liber Usualis, la que coincide ciertamente con su estructura melódica.

${ }^{69}$ Grandela ("Letelier Llona, Alfonso", p. 899) afirma al referirse a Nocturno que el O vos omnes corresponde a la liturgia de Semana Santa. Esto es cierto, pero debe aclararse que la versión gregoriana de este canto y que corresponde a esa festividad es una antífona en el modo VIII. Por tanto no es la misma que aquella de la fiesta de la Virgen de los Dolores (verso del Alleluia en modo II) y, de acuerdo a lo que planteo en este estudio, es esta última versión la que Letelier seguramente consideró. 
dente gradual. En la frase 3, "Attendite" tomó nuevamente las primeras tres notas (La, Si bemol, Sol) y permutó su orden (Sol, Si bemol, La, Sol). En el caso de la frase 4, "Et videte", extrajo el giro de quinta descendente gradual, suprimiendo las notas pares y bajando en un semitono la nota La.
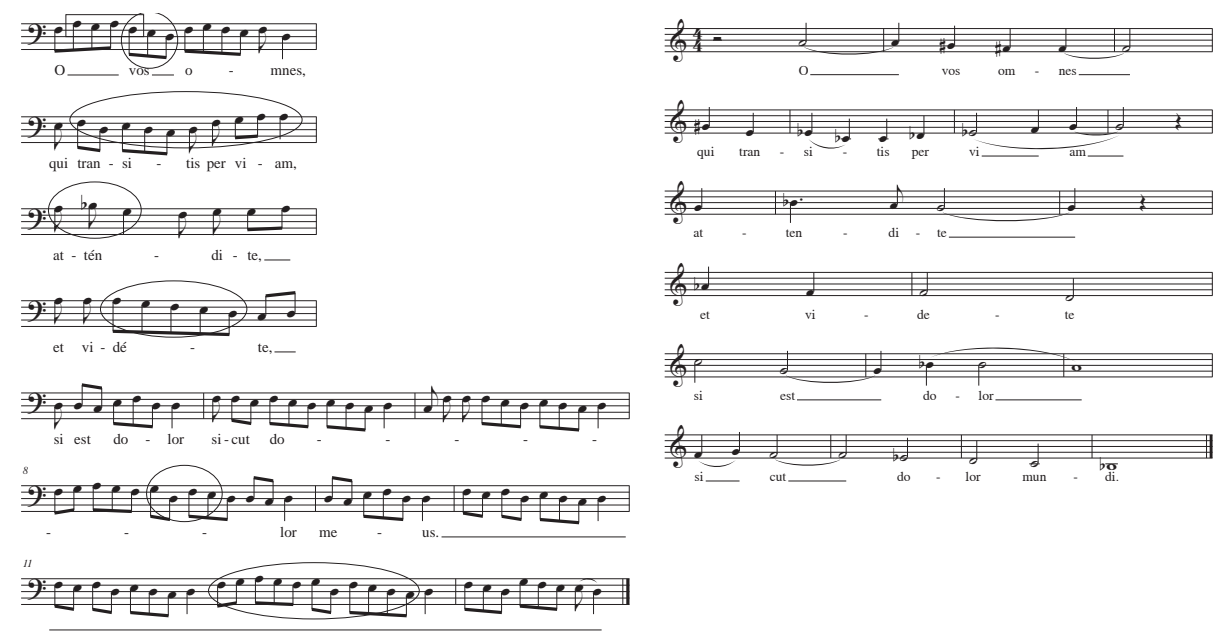

Ejemplo 6 a (izquierda). O vos omnes (pieza gregoriana)

Ejemplo $6 b$ (derecha). Nocturno, O vos omnes (cc. 85-100)

Respecto de la frase 5 "Si est dolor sicut dolor", se limitó a solo las cuatro notas encerradas en óvalo (Sol-Re-Fa-Mi) y mantuvo su estructura interválica (cuarta descendente, tercera menor ascendente, semitono descendente), pero transportada (Do-Sol-Sib-La). Por último, en la frase 7, la que corresponde a la palabra "meus" en el canto original y a "mundi" en el texto de Letelier, el compositor habría extraído el ámbito y la trayectoria básica del extracto melismático encerrado en óvalo, una sexta descendente de La a Do, transportada de Sol a Si bemol.

Este nivel de elaboración temática a partir del canto litúrgico mencionado no resulta extraño al considerar procedimientos similares en las tres obras anteriormente presentadas, especialmente en el caso del Soneto de la muerte $n .^{\circ}$ 3. Sin embargo, a diferencia de lo que ocurre con el Salve Regina en dicha obra, en Nocturno estamos ante lo que podríamos denominar una cita parentética transformada ${ }^{70}$, ya que el $O$ vos omnes es citado una sola vez, al

\footnotetext{
${ }^{70}$ Considero aquí "transformación" tal como Giulio Bas define "amplificación", es decir: "cuando el tema, aún conservando más o menos identificables algunos de sus rasgos exteriores, sea en el giro melódico, en el ritmo o en la armonización, es profundamente, íntimamente transformado, transfigurado en su contenido musical y expresivo". Giulio Bas: Tratado de la forma musical, Buenos Aires, Ricordi, 1975,
} 
final de la pieza, pero elaborado de tal manera que la melodía original no resulta reconocible. Este factor, junto con la polifonía instrumental y disonante que envuelve al canto, permite confirmar, como dice Georges, que se trata de un "compendio del pensamiento musical" de Letelier, en el cual el canto gregoriano cumple un papel fundamental. En este caso, en términos de una fragmentación melódico-tonal que oculta el canto original, como si la fe del compositor igualmente se diluyera ante el dolor y la angustia existencial que permea su texto, pero sin desaparecer del todo.

\section{Perspectivas}

En 1968, con ocasión de la incorporación de Letelier a la Academia Chilena de Bellas Artes, Domingo Santa Cruz expresó que en su obra y estilo en general se manifiesta una "vena dramática", una "angustia metafisica fundamental" vinculada con "la honda visión de los místicos españoles" adelante añade que "Letelier, como preferencia, está más en el lado derecho del Rhin que en el izquierdo [...]. Lo dramático y trascendente nos viene de España pero con ropaje enhebrado desde el gran Tomás Luis de Victoria a Bach, Wagner y Schönberg",72.

En este discurso Santa Cruz construyó una imagen de Letelier como un compositor que conjugaría en su obra el misticismo musical español (Victoria) con la tradición canónica y la contemporaneidad musical de cuño germánico (Bach-Wagner-Schönberg). Respecto de esa veta "mística musical española" en Letelier, Santa Cruz señala:

Como expresión auténtica de esta piedad es el canto gregoriano, lo excelso. Hoy lo vemos [a Letelier] campeando por defender este fundamental tesoro, frente a una barbarie populista que asoma demasiado, en la preocupación de "la recherche du temps perdu" que inquieta al catolicismo posconciliar. Letelier venera lo gregoriano; las volutas y melismas del gradual se advierten en su obra más aún de lo que con intención citó, el lenguaje modal es constante ${ }^{73}$.

Claramente Santa Cruz asumía la veracidad del "mito del misticismo musical español" que hoy ha sido severamente cuestionada ${ }^{74}$. Sin embargo,

p. 212. Si no fuera por la presencia del texto original, esta transformación de los motivos melódicos de $O$ vos omnes permitiría calificarlos perfectamente como "sumergidos" como diría Jambou ("Músicas del siglo XVI...", pp. 1054-1055).

${ }^{71}$ Domingo Santa Cruz Wilson: "El Compositor Alfonso Letelier", RMCH, 21, 100, 1967, pp. 12 y $15-17$.

${ }^{72}$ D. Santa Cruz Wilson: "El Compositor Alfonso Letelier...", p. 23.

${ }^{73}$ D. Santa Cruz Wilson: "El Compositor Alfonso Letelier...", p. 16.

${ }^{74}$ Pilar Ramos López: "Mysticism as a Key Concept of Spanish Early Music Historiography", Early Music. Context and Ideas II International Conference in Musicology, Cracovia, 2008, pp. 69-82 (www.academia.edu/7787362, consulta 26-6-2019). 
aunque Letelier no haya sido exactamente un "místico"75, no se puede desconocer su profesión religiosa explícita ni tampoco, lo que aquí es el tema fundamental, la relación entre esa profesión y la incorporación del canto gregoriano en obras como las que se han tratado aquí. El carácter religioso en sentido amplio, como fue definido al comienzo de este estudio, de estas obras explica de manera casi "natural" la incorporación del canto gregoriano en ellas.

Se ha visto que tanto el discurso poiésico, como el de recepción de estas obras destaca este hecho. Sin embargo, se ha observado que los procedimientos tanto de cita como de elaboración de las piezas gregorianas son diferentes: desde la selección de extractos como material temático puramente musical en Soneto de la muerte $n .^{\circ} 3$ y Nocturno hasta la cita de frases melódicas completas en Vitrales de la Anunciación I y IV (con la letra de los cantos) y la Sinfonía "El Hombre ante la Ciencia", mediante citas parentéticas variadas, transformadas, citas expandidas o intertextos vocales. Un aspecto interesante que comparten las cuatro obras escogidas es que el material gregoriano se presenta en las secciones finales de cada una, lo que incluye al Soneto de la muerte $n .^{\circ} 3$ en su integridad al considerar que es la tercera y última parte de la obra completa. Esto indica que para Letelier el canto gregoriano constituía no solo una fuente de material musical sino un recurso expresivo clave para subrayar musicalmente el sentido de sus obras.

Los diferentes tipos de citas musicales de canto gregoriano en estas piezas tienen incidencias estructurales y semióticas, así como su tratamiento devela ciertas recurrencias en las estrategias creativas de Letelier. El Salve Regina en Soneto de la muerte $n .^{\circ} 3$ es la base del entramado polifónico y su diálogo "sin palabras" con los versos de Gabriela Mistral adquiere el sentido de una doble súplica. En el caso de Vitrales, el Regina coeli laetare en el Vitral I es tratado al modo de organum (lo que permite establecer redes intertextuales con la polifonía gótica que se escuchó en las catedrales que hoy se destacan por sus vitrales) y la combinación de dos versiones litúrgicas del Rorate coeli desuper en elVitral IV funciona como fundamento de la elaboración melódica, polifónica y del plan tonal, así como del énfasis en el sacrificio del Mesías anunciado. El Alleluia Veni Sancte Spiritus en el último movimiento de la Sinfonía "El Hombre ante la Ciencia" funciona de un modo similar al

${ }^{75} \mathrm{Si}$ el misticismo es cognitio Dei experimentalis ("conocimiento de Dios por medio de la experiencia") como lo definía santo Tomás de Aquino, no tenemos información de que Letelier haya tenido vivencias místicas efectivas. Además, a pesar del alto porcentaje de música religiosa en un sentido amplio que presenta su catálogo, en este encontramos también música secular. Y a diferencia de grandes figuras del misticismo español como san Juan de la Cruz o santa Teresa de Ávila, e incluso de los compositores cuya obra ha nutrido el mito del misticismo musical español como Victoria, Morales o Guerrero, Letelier no abrazó la vida sacerdotal ni jamás fue un músico dedicado a la iglesia, pese a su preocupación por la actividad musical en ella después del Concilio Vaticano II. 
Salve Regina en Soneto de la muerte $n .^{\circ} 3$, piedra angular del tejido orquestal y diálogo "sin palabras" con el texto entonado por la cantante y que permite identificar la "Presencia" en el Espacio-Tiempo con el Espíritu Santo. Mientras la fragmentación melódico-tonal del O vos omnes (la que nos recuerda aquella elaboración melódico-modal en el Rorate coeli desuper de Vitrales) en medio de un idioma disonante en Nocturno, se puede relacionar con esa "crisis de fe" que Miguel Letelier Valdés reconoció en los últimos años de vida de su padre.

La presencia del canto gregoriano en estas obras de Letelier se puede vincular además con un doble propósito: la afirmación de su relación con la tradición musical euroccidental y la oposición al destierro del canto gregoriano en las prácticas litúrgicas, esto último especialmente en el caso de la sinfonía y de Nocturno. Según López-Cano ${ }^{76}$, las prácticas intertextuales son fundamentales para la construcción de una cultura musical, y para Nommick ${ }^{77}$ develan las interacciones entre tradición y modernidad. El idiolecto musical de Letelier, como ha planteado el discurso de recepción de sus obras, se relaciona sin duda con la modernidad musical en términos de estilos (impresionismo, expresionismo, neoclasicismo), pero se arraiga también en la tradición, donde el canto gregoriano ocupa un lugar histórico reconocido.Y, por otra parte, como ya se ha dicho, Letelier se opuso al movimiento litúrgico posterior al Concilio Vaticano II que resultó en la eliminación casi absoluta del canto gregoriano en las iglesias católicas de Chile e Iberoamérica. Mediante la incorporación de piezas de este repertorio a sus obras de concierto, especialmente aquellas posteriores a la década de 1960, Letelier declaraba su adhesión a este repertorio y su protesta, aunque fuera en la sala de conciertos y no dentro de los templos, frente a su desaparición en los oficios litúrgicos.

La presencia del canto gregoriano en la música de Alfonso Letelier resulta, pues, altamente significativa en su música religiosa. En el caso de las cuatro obras abordadas aquí, queda pendiente la profundización en aspectos tales como la armonización, la orquestación o la elaboración contrapuntística y sus probables vínculos intertextuales. Además habrá que profundizar en la observación y estudio de citas y elaboraciones de canto gregoriano en el resto del legado religioso de Letelier, así como en sus obras profanas, al igual que examinar casos similares entre otros compositores o compositoras en Chile o Iberoamérica.Y, por supuesto, examinar otros casos de prácticas intertextuales más allá del canto gregoriano dentro del repertorio académico iberoamericano.

\footnotetext{
${ }^{76}$ R. López Cano: Música dispersa..., p. 29.

${ }^{77}$ Y. Nommick: "La intertextualidad...", p. 806.
} 
Apéndice

Textos usados en obras de Alfonso Letelier

Soneto de la Muerte $n .^{\circ} 3$ :

"Malas manos" (Gabriela Mistral) ${ }^{78}$

Malas manos tomaron tu vida desde el día

en que, a una señal de astros, dejara su plantel

nevado de azucenas. En gozo florecía.

Malas manos entraron trágicamente en él...

Y yo dije al Señor: "Por las sendas mortales le llevan, jsombra amada que no saben guiar! ¡Arráncalo, Señor, a esas manos fatales

o le hundes en el largo sueño que sabes dar!

¡No le puedo gritar, no le puedo seguir!

Su barca empuja un negro viento de tempestad.

Retórnalo a mis brazos o le siegas en flor".

Se detuvo la barca rosa de su vivir...

¿Que no sé del amor, que no tuve piedad?

¡Tú, que vas a juzgarme, lo comprendes, Señor!

El Hombre ante la Ciencia ${ }^{79}$ :

Aliento del tiempo y del espacio.

Presencia inmanente del transcurso.

¡Oh, Energía!

Es verdad que tu esencia permanece

aunque de atavío mudes;

ya impulses el hirvor (sic) de la materia,

seas fluido misterioso, radiación,

luz, calor, desplazamiento.

Si es así ¿por qué, entonces,

desde la profundidad de cada cambio que originas

dejas huir sin retorno, inexorable,

un leve girón de tu existencia?

yo te llamo fantasma del silencio,

campo inerte del sosiego, sombra de quietud,

emparejamiento.

No nos dices dónde vas ni dónde llegas.

¿Es el abismo tu morada?

¿Cabe en ella, acaso,

la enormidad de tu alquimia?

¿Es que en tiempos siderales

sin descanso te acumulas

\footnotetext{
${ }^{78}$ Gabriela Mistral: "Los Sonetos de la Muerte", RMCH, 35, 153-155, 1981, p. 83.
}

${ }^{79}$ C. Riesco: "Sinfonía 'el Hombre ante la Ciencia", pp. 80-81. 
hasta que el Universo apagues

hasta que mudo lo vuelvas, tibio, yerto?

Desafiando la apariencia, los sentidos, acercó el hombre ¡Oh, Energía! su rostro

al reverso invisible de tu rostro;

magnitud en la que nada sino el número

revela la deriva por donde lanzas al mundo

hacia aquello más y más probable.

Vorágine de desalojo, ¡ciega raíz del caos!

¿Cómo es que hendiéndose tu entraña,

roto el azar, surge cual alba que despunta

el signo improbable de la vida?

Tránsito breve, supremo remontar

que allá donde confina su alborada

alzan vuelo la mente, el amor, la voluntad.

Desde entonces, un éxtasis ardoroso

-espejo del saber- estremece el pedazo de Universo

que es el hombre, ánfora leve

apenas capaz de sostener el peso

del asombro, del anhelo, del dolor.

Bendita sea, Espacio-Tiempo

la agitación de tu hondura

porque una Presencia en tu seno

trocó el acaso por destino.

Nocturno $^{80}$

Siento pasar el tiempo

ahora con premuras de espacio

y mientras el camino se acorta

me pregunto.

Mas no hay respuesta a lo que encubre

esta niebla turbadora que lo invade.

En su claro-obscuro la duda

se arremolina lenta, amenazante,

despedazando amores, esperanzas;

o volviendo a la razón fantasma

que en su incansable afán

de cabalgar en la luz

solo vislumbra senderos

que emanan incertidumbre.

${ }^{80}$ Cristián Guerra Rojas: "La música religiosa de Alfonso Letelier en el marco de la promoción institucional de la Universidad de Chile: Vitrales de la Anunciación (1950) y Nocturno (1991)", Actas de la XXIII Conferencia de la Asociación Argentina de Musicología y XIX Jornadas Argentinas de Musicología del Instituto Nacional de Musicología, Pablo Jaureguiberry, Clarisa Pedrotti (eds.), Buenos Aires, Instituto Nacional de Musicología Carlos Vega, 2019, pp. 172-183. 
¿Qué es la vida? ¿qué la muerte?

Abismal enigma donde el sufrir no redime

Y sí aniquila. Pues ni el lejano hilo tendido

desde lo Increado a la existencia

ni las ansias de prodigio

podrán decirnos un día

que el dolor es manantial y no desierto.

O vos omnes qui transitis per viam, attendite et videte:

Si est dolor sicut dolor mundi.

Recibido: 28-2-2019

Aceptado: 31-5-2019 